\title{
Los presidentes de la Chancillería de Granada en el siglo XVIII
}

\author{
Pedro Gan Giménez *
}

La Real Chancillería de Granada, erigida en 1494 y con sede en Ciudad Real hasta su traslado a la ciudad, poco ha reconquistada, en 1505, ha sido objeto de estudio en diversos trabajos de los últimos años ${ }^{1}$. Así se ha cubierto un hueco incompatible con su importancia dentro de la historia general de las instituciones españolas del Antiguo Régimen y de la particular de una región, la España de la Mancha, Extremadura, Murcia y Andalucia, y de una ciudad, Granada, en la que tanto influyó política, social y económicamente. No hay que recordar que la Chancillería y sus magistrados no eran sólo un órgano judicial sino también administrativo, especialmente a través del Real Acuerdo y de su cabeza el Presidente ${ }^{2}$. Lo que además se acentúa en el caso de Granada por el mayor alejamiento de la Corte y las especiales características de la ciudad en que tiene su sede, todavía en un principio un país islámico. Donde conviven diversos poderes que también iniciaban aquí su rodadura y entre los que serán frecuentes los conflictos.

Pero en el siglo XVIII no es igual la situación. La Chancillería tiene ya un arraigo de dos siglos y las otras autoridades locales han experimentado la evolución que trae consigo el trascurso del tiempo y el reciente cambio dinástico. Los Presidentes de aquélla tienen otras características personales. Durante el XVI y primera mitad del XVII han sido casi todos,

* Profesor titular de Historia Moderna. Universidad de Granada.

P. Gan: La Real Chancillería de Granada (1505-1834). Granada 1988. A. RuIz Rodri GUEZ: La R. Chancilleria de Granada en el siglo XVI. Granada 1987

2 Como decimos más adelante con remisión al Libro Secreto, ff. 289, 309. 
de forma semejante a lo ocurrido en el Consejo Real, eclesiásticos con dignidad episcopal o que verán recompensada de este modo su gestión en la Chancillería. Sólo las difíciles horas de la Guerra de Sucesión quebrarán momentáneamente esta trayectoria con el Presidente Miguélez. Y por eso comenzaremos con él estas breves semblanzas, prescindiendo de un par de otros anteriores.

Otro factor que conviene destacar para este período es la breve duración de la Presidencia. Pocos son los que superan el quinquenio, salvo Miguélez y Fuentes y cuando declina el siglo Maraver, Velarde y Mata, aunque no por mucho más tiempo, salvo el primero, y ello por el motivo señalado. Sobre todo desde (1756), que una Resolución del Consejo determinó la adquisición automática de plaza en el de Castilla con sólo tres años de Presidencia, aunque todos los magistrados de la Chancillería disfrutaban desde antiguo del tratamiento honorífico, de poder titularse del Consejo de Su Majestad y un Presidente del XVII, probablemente Ríos y Guzmán, llegara a redactar y publicar un alegato en que defendía su equiparación con los Consejeros (1664) ${ }^{3}$.

Así que vamos a ocuparnos de veintidós Presidentes en este siglo. Los de Valladolid serán veinticuatro o veinticinco. Veremos cómo poco a poco va cambiando su carácter conforme avanza la nueva administración borbónica y su intervención en los asuntos más variados que se plantean en su ámbito territorial se hace notar, especialmente en la vida ciudadana, rompiendo los límites que en Granada y Valladolid habían fijado sendas Concordias del siglo XVI, cuyo cumplimiento todavía reclamaba la ciudad de Granada en 1731.

Facilita nuestra tarea el que, a pesar del lamentable estado en que a lo largo del tiempo quedó la documentación específica del Real Acuerdo, órgano gubernativo de la Chancilleria, se nos haya conservado un mayor volumen para este siglo XVIII ${ }^{4}$. También que se hayan realizado algunos trabajos sobre esta historia social de la Administración

${ }^{3}$ Señor. Es de gran mortificación para mi, que la precisa obligación de conservar el grado de la Dignidad con que V. Magestad se sirvió honrarme... Presidente de Chancilleria, de preferir a los Consejeros del Consejo...

4 Aparte de los llamados Libros de RR. Cédulas, de los que tenemos cuatro (187 a 190) para este periodo, la comprendida en los legajos 321-4280 a 322-4448. Cfr. Gan, Chancilleria, cap. I. 
española ${ }^{5}$. Las preguntas son: ¿cuál es el origen de estos Presidentes, cuál su formación académica, cuál su cursus honorum hasta llegar a tan alto cargo, cuál su destino final? Vemos así cómo los más proceden de la Regencia de otras Audiencias, o son Alcaldes de Corte en el Consejo de Castilla, o Fiscal de éste, o Gobernador de Vizcaya, o sólo Consejero del de Castilla. Luego, y en lo posible que no es mucho por lo que se ha indicado, ¿cuál fue su actuación en los breves años de su Presidencia en Granada?

(1705-1715) JUAN MIGUÉLEZ DE MENDAÑA OSORIO. Colegial del de Oviedo en Salamanca. Inquisidor. Los Paseos del P. Velázquez Echeverria lo pintan asi: «Inquisidor de esta ciudad... merece particular atención en mis memorias, y es de aquellos hombres antiguos, que roban por justicia el respeto, y el afecto natural». Esto se escribe en 1765, cuando han transcurrido ya cincuenta años desde que salió de Granada como Obispo de Tortosa. Muere en 1716. Su precipitada venida a la ciudad, que realizó en pocos días de viaje desde Madrid, pues fue nombrado en 12 de junio y se posesionó el 23, prescindiendo, según se ordena en el mismo título, del acostumbrado ceremonial para la entrada, está motivada por la fracasada conjuración austracista, que fue rápida y severamente reprimida ${ }^{6}$. El dia 9 habia sido depuesto su antecesor el Presidente Uriarte Ysunza y llevado a Madrid, pero no preso como señala el cronista. Miguélez recibirá honores de Consejero (1706). Después y al formarse una Junta de Guerra en Granada ésta organizará compañias, una de ellas "en el quarto de Su Señoria», en que se integraban ministros y oficiales de la Chancilleria. Varios Oidores forman parte también de aquella Junta y marcharán a diversos lugares del Reino para acopiar víveres necesarios en la defensa de Murcia.

Es la suya una de las más largas Presidencias de todos los tiempos, propiciada por las dificiles circunstancias que interfieren el curso normal de la vida administrativa. Se ha encontrado la persona que cumple su función aunque no fuera demasiado brillante y no hay por qué mudarlo en los tres a cinco años de costumbre. Los problemas internos de la

${ }^{5}$ En especial los trabajos de P. Molas y de M. ${ }^{a}$ A. Pérez Samper en Historia Social de la Admon. Española, Barcelona 1980 y en la revista Pedralbes 1 y 2, Barcelona 1981 y 1982.

${ }^{6}$ M. RaBASCO: “Actitud de la ciudad de Granada en la sucesión de Felipe V", en Anuario de $H^{a}$. Moderna y Contemporánea, 1, Granada 1974. P. GAN: “Tres siglos de revueltas granadinas", en Granada Provincia, 1981. 
Chancillería serán, sobre todo, de tipo funcionarial. La creación de nuevas Audiencias conforme al Decreto de Nueva Planta da origen al recurso de proveer las plazas de aquéllas mediante nombramientos para la Chancillería de Granada, donde se jura el cargo y de donde se sale inmediatamente hacia el nuevo destino. De forma que aunque haya en la Audiencia granadina plazas por cubrir efectivamente, la nómina está artificialmente abultada y hay dificultades para pagar los sueldos.

A lo que se añaden otros problemas, no políticos pero no menos importantes. Como la plaga de langosta de 1708. Según los Anales ${ }^{7}$ :

"Este año fue el que llamaron de los Palenques, porque las aguas duraron todo el invierno y primavera. Valió la fanega de trigo 100 reales. El Palenque duró desde agosto hasta junio del año siguiente".

$Y$ en los mismos y para 1712 :

"Se empezó a cobrar un donativo que echó el Rey, pero no consiguió su cobranza, porque las mujeres y muchachos a palos y pedradas lo impidieron. La Ciudad tomó el medio de pedirlos prestados a diferentes sujetos los 40 mil pesos, que eran los que se pedían y los dio de pronto al Rey; después los cobró en diferentes arbitrios".

Otro autor nos habla de un motín (1714) iniciado por los fabricantes, maestros y oficiales de la industria sedera, a causa de los gravámenes impuestos y de haberse decretado la prisión de los mayores de las fábricas, por no hallarse ajustada la confección de algunos tejidos a lo preceptuado en las pragmáticas.

1715-1723. MANUEL DE FUENTES Y PERALTA. Colegial del de Cuenca en Salamanca. Era alguien que volvía a Granada, pues de Juez de Sevilla pasó a Oidor en 1707, aunque a los dos meses marchaba a la Audiencia de Aragón. Luego será Oidor de la Contaduría y Presidente de la Sala de Alcaldes. Reinstaura la serie de Presidentes seglares que

${ }^{7}$ Anales de Granada, en La Alhambra, 1900 y Noticias curiosas de Granada, en lbidem, 1901. Refundidos por L. MORELL: Efemérides granadinas, Granada 1892. 
ya no se interrumpirá. Es uno de los que poco puede decirse, salvo que durante su mandato quedó resuelto, en contra de la Chancilleria, el más que centenario enfrentamiento con el Arzobispado por la cuestión de la Silla en la procesión del Corpus (1721) ${ }^{8}$.

1723-1728. LUCAS MARTíNEZ DE LA FUENTE. También Colegial del de Cuenca. De la orden de Calatrava. Catedrático de Valladolid. Fiscal de lo Civil en Zaragoza, también será Oidor en Granada (1709) y precisamente para sustituir a uno de aquellos pasajeros, Holguin, al que por cierto se le reservó su plaza durante casi dos años. Por su parte, a Martínez de la Fuente se le consolidará su empleo en Granada (1711) con la antigüedad de su primera plaza en la judicatura. Será Regente de Canarias (1718) y de Oviedo.

1729-1733. BARTOLOMÉ (DE) HENAO LARREÁTEGUI Y COLÓN. Colegial del de Oviedo en Salamanca y Catedrático de Prima de Cánones. Alcalde de los Hijosdalgo y Oidor de Valladolid. Corregidor de Guipúzcoa. Regente de Galicia. Representa el caso, desde luego no raro, de las familias que logran introducir en la Administración española a varios de su estirpe y que se relacionan con otras semejantes por vínculos matrimoniales. Limitándonos a los que pasaron por la Chancilleria Granadina, tenemos a su padre Juan de Heno y Monjaraz (Oidor en 167579) y a su hermano Baltasar (Fiscal y luego Oidor entre 1707-25). Su madre, con diez hijos, doña Teresa Colón de Larreátegui era hija del Consejero Martin de Larreátegui y también hermana y tía de los Oidores Pedro (1694-98) y Mariano (1774-78 y antes Alcalde de Hijosdalgo). Su apellido Colón no requiere mayor explicación.

1734-1738. JUAN FRANCISCO DE LA CUEVA Y ZEPERO. Colegial del de Maese Rodrigo de Sevilla. De la orden de Calatrava. Alcalde y Oidor de la Audiencia de Barcelona. Regente de Navarra. De Lucena, es uno de los pocos andaluces que ocupan este cargo. Hay un Abogado granadino (?) Tomás, quizá su padre, que firma un alegado (1682). El lenguaje popular granadino ha conservado la expresión año de la nanica para referirse a una fecha antigua pero indeterminada. Pues bien, su explicación está en los citados Anales: Este año (1734) empezó sin Ar-

${ }^{8}$ Cfr. P. GaN: “En torno al Corpus granadino del siglo XVII», en Chronica Nova, 17. Granada 1988. 
zobispo (Perea murió en junio de 1733), sin Presidente, sin Provisor y sin pan, pues valía cada hogaza de a libra 12 cuartos. El comienzo de su Presidencia no le era muy favorable: sequía y luego en cambio una tormenta otoñal que hizo salirse de madre al Genil. Según las Efemérides:

"Después de una gran calamidad de grandes hambres y sequia, pues no llovia en todo el año, por lo cual se secaron los rios, y hasta los animales perecian de sed y hambre, los molinos se pararon y todos fallecian, vino una avenida prodigiosa al rio Jenil, y se notó que traia gran cantidad de peces(!). Llovió tanto en los dias siguientes, que pareció se inundaba la ciudad".

Al año siguiente la situación pudo desembocar en un motín que abortó la autoridad:

«Aparecieron por la mañana (24 mayo) puestas horcas en las plazas de Bibarrambla y Nueva (la más concurrida y céntrica y la otra en que se alza la mole de la Chancilleria) y tomadas las bocacalles con ministros de justicia, clero y verdugo, con cuyas medidas se aplacó el pueblo sublevado contra el Corregidor por la carestia de pan y otros comestibles".

Este Intendente-Corregidor era D. Clemente de Aguilar, que ya lo había sido en Valencia y que antes de tres meses seria sustituido por $D$. Juan de Molina y Oviedo, hermano del Presidente del Consejo luego Cardenal Gaspar de Molina.

1738-1740. JOSÉ DE ARZE Y ARRIETA. Colegial del de Oviedo de Salamanca. De la Orden de Santiago. Juez Mayor de Vizcaya; también Corregidor y Gobernador. Oidor de Valladolid. Regente de Galicia. Si hemos de acoger, aunque con las debidas reservas, los elogios póstumos de altos personajes, podremos tomar en cuenta los datos que nos proporcionan. Según el Fúnebre panegirico del Presidente (muerto en julio) a cargo de Fr. Antonio de Pineda, había nacido en Valladolid en los últimos días de 1674. A través de su confesor, el luego tan conocido Padre Rávago confesor regio, socorría 150 pobres; recitaba todas las mañanas estando aún en la cama el catecismo para purgar una falta de aplicación en esta materia cuando era adolescente, práctica que no agra- 
daba demasiado a su esposa doña Catalina de Feloaga. Atendía y escuchaba antes al pobre que a los poderosos que le visitaban.

1740-46. ARIAS DÍAZ CAMPOMANES Y OMAÑA. Colegial del de Oviedo en Salamanca y Catedrático. Alcalde del Crimen (1726) y Oidor (1732) en Granada. Alcalde de Corte (1736). Al llegar a este Presidente tenemos ya disponible, aunque no para muchos de nuestros biografiados, una documentación muy valiosa. Un único volumen de los varios que componian el Libro Secreto de la Presidencia de Granada ${ }^{9}$. Reseñaban en él al terminar su mandato los principales acontecimientos de su gestión y debemos suponer que la autocomplacencia se vería frenada por el pensamiento de que su sucesor iba a ser enseguida su primer, curioso y crítico lector. Se incluyen además documentos justificativos de lo que exponen cuatro de nuestros Presidentes entre 1740-70, si bien con un hueco entre 1752-66.

Es Campomanes el que abre este tomo. Los Informes lo definian como «sujeto de más habilidad que literatura, salió cortísimo de la Universidad por su ninguna aplicación. Es de genio bastante vivo". Como tenemos su gestión reflejada en el Libro secreto advertimos que había aprendido, al menos en lo referente a su caracter, a dominar su impaciencia. En todos los casos que se le presentan va siguiendo las instrucciones que recibe de Madrid a través de su Presidente el Cardenal de Molina. Antes de venir a Granada a posesionarse y sin duda en la protocolaria visita a tan alto personaje, éste, nos dice, le ordenó hiciera cumplir las Leies de estos Reinos, Ordenanzas, y Visitas de este Tribural, y autos acordados del Consejo. Lo que parece obvio pero también indicativo de cierto relajamiento en la Chancillería granadina. Fruto de ello será su Auto de Buen Gobierno (1741) que le fue aprobado por la Superioridad en 1742 y cuyo texto incluye en el Libro, así como otros documentos, precediendo al relato de su gestión ${ }^{10}$.

Los problemas locales a que hizo frente están representados por temas tan concretos como: abasto de carnes; empedrados de vías públi-

${ }^{9}$ Libro 197, con $800 \mathrm{ff}$. de los que sólo faltan unos pocos. Hemos hecho una especie de breve indice en nuestra Chancilleria, 48-50.

${ }_{10}$ La parte referente a Campomanes en ff. 193-223. Los Informes para los magistrados de la Chancillería granadina en el siglo XVIII, en M. ${ }^{a}$ A. PEREZ SAMPER: "Los Ministros...", en Actas II Coloquios de H. ${ }^{a}$ Moderna de Andalucia, t. II. Córdoba 1983. Aparte de estar limitados al período $1742-60$, son vagos y generalmente reiterativos. 
cas; «juegos prohividos en esta Ciudad, así en casas particulares, como en sitios exemptos de la jurisdizión ordinaria»; epidemia de Málaga - de la que por cierto era Obispo el Presidente del Consejo- a donde envía dos médicos «en la inteligenzia de que no siendo caso claro de Peste desvaneziesen qualquier voz que se subsitase sobre ella". Aunque ha de reconocer que "era mucha la gente que moria". También y como veremos más adelante ya había surgido el conflicto entre la Ciudad y la Real Maestranza a causa de las corridas de toros y Campomanes propiciará la primera de la serie de Concordias entre ambos Cuerpos:

"Lo conseguí, pues conferenziándose conmigo, se concordó en que se turnase un año; que esta ciudad hiziese las fiestas que quisiese, y al siguiente las Maestranzas" ${ }^{11}$.

Un capitulo de su relato se dedica al Pósito que no funcionaba bien, sino "con notables atrasos en sus reintegraciones". Va a lograr que se hagan y "algunas desde el año de 1708". Todo ello será recompensado con los honores de Consejero en 1742 y con una plaza en 1745 con la antigüedad referida: «juré dichos Honores, y antigüedad en manos de $\mathrm{Sr}$. D. Joseph Ruiz de Castro Oidor Decano de este Tribunalm. El final de su relato se rubrica con unas muy cristianas líneas:

"Hoc omne opus sit ergo ad Dei placitum, et ad laudem eius immensae misericordiae et etiam sacratissimae Virginii Mariae, ut Divinum auxilium Me ducat ad sempiternam gloriam. Amen." ${ }^{12}$.

1746-1748. JUAN FRANCISCO DE ISLA Y VALLADO. Burgalés (Isla). Colegial de San Bartolomé en Salamanca y Catedrático. Juez del Arzobispado de Santiago. Fiscal de Cataluña (1724). Oidor de Valladolid (1733). Regente de Valencia (1739). Breve será la Presidencia de Isla que había comenzado con los mejores auspicios. Conforme a sus propias palabras y a los Informes tenia todas las cualidades necesarias para el cargo, donde podría aplicar sus ideas regalistas. En vísperas de su entrada hace la acostumbrada pernocta en la proximidad de Granada y allí

11 f. 213.

12 f. 223. 
le esperaban nada menos que mis cinco Colegiales, dos Oidores y tres eclesiásticos. Lógicamente su narración no puede ser muy larga para tan breve período de Presidencia; pero además es poco interesante ${ }^{13}$. Al coincidir con la muerte de Fernando VI y el acceso del nuevo Monarca, leemos su relato sobre honras fúnebres, lutos, levantamiento de pendones, nuevos sellos reales. En 1747 se celebran Fiestas Reales, con sus corridas de toros y problemas con el Arzobispo y la Inquisición por cuestiones de preeminencia, llegando incluso a ordenar el Presidente la suspensión de las fiestas, mientras elevaba consulta al Consejo sobre el incidente, "relacionando el exceso, y ser contra el respeto, autoridad y veneración de V. R. Persona en esta Ciudad», a quien representaba la Chancillería. Tanto esta consulta como la subsiguiente $R$. Cédula vienen intercaladas en el relato. Triunfó el Presidente, pero en la procesión del Corpus del año siguiente (1748), la Inquisición volvió a repetir su postura. Menos airoso para el Tribunal fue el resultado del lance con un miembro de la nobleza representada por el Marqués del Salar, pues se le condonó la sanción pecuniaria que le había sido impuesta y el Presidente recibió poco antes de dejar el cargo la correspondiente Resolución en que se "tratava de riguroso, e indiscreto su modo de proceder... Aunque sobre las expresadas vozes de riguroso, indiscreto, y otras, determinó (el Real Acuerdo) representar a S. M. lo conbeniente, como asi lo hizo".

Tres jornadas trágicas señalan el fin de la Presidencia de Isla: terremoto de 6 de octubre corrida de toros del día 7 en que "se cayeron las ventanas que de madera habian hecho enfrente del Rastro, donde perecieron seis o siete personas, y se lastimaron infinitas, por lo que cesó la función”. Sobre todo el motín del 8:

"Habíanse retraido dos defraudadores de las Rentas Reales en el templo de Nuestra Señora de las Antiguas, y hallábase cercado de guardas algunos dias; el Corregidor dispuso que fuesen aprisionados, pero ellos se resistieron en la torre y tocaron las campanas a entredicho, amotinándose el pueblo que la emprendió a pedradas con el Corregidor, guardas y ministros, y perseguida la plebe por los soldados... penetró en el Ayuntamiento... asomándose al balcón haciéndose uno Corregidor y otros Veinticuatros... subieron en procesión a la Chancillería pidiendo la supresión del impuesto y la baja del pan; salieron los

${ }^{13}$ Ocupa los ff. 224-246. 
Señores de las Salas, se presentaron en el cuarto del Sr. Presidente..." ${ }^{14}$.

Nada de esto nos cuenta Isla, quien pone su rúbrica final en el Libro Secreto en 20 de noviembre. Quien lo hará y con extensión es su sucesor.

1748-1752. FRANCISCO DE CASCAJARES CASTILLO BLANCAS $Y$ PASTOR. Aragonés (Calanda, 1692). Colegial y Catedrático de Huesca. Alcalde de Huesca. Alcalde del Crimen de Cataluña (1725). Oidor de Aragón (1733). Alcalde de Corte (1748). Aunque Cascajares, con gran delicadeza, señale como causa del cese de Isla en la Presidencia de Granada su promoción al Consejo de Castilla y otros autores lo atribuyan a un simple retraso en comunicar a Madrid los acontecimientos, el texto del Libro Secreto es concluyente:

"Se dió cuenta a S. Majestad por el correo de la misma noche ... y a los quince días de este suceso, avisó el Exm. ${ }^{\circ}$ Sr. Marqués de la Ensenada haver aprovado S.M. quanto se havia executado por la Chancillería, dándose por bien servido; pero a pocos Correos se experimentó que, ofuscando todos estos hechos el Corregidor con los testimonios, que a su contemplación fabricaron algunos escribanos de su devoción, consiguió se trasmutase la anterior providencia” ${ }^{15}$,

Tal cambio consistió en el envio de tropas al mando del Teniente General D. Juan de Villalba con «facultades amplísimas del Rey para conocer de este asunto". Y que Cascajares mereciese de

«... la benignidad del Rey (Dios le guarde) el honor de mandarme venir a ocupar esta Presidencia, siendo Alcalde más moderno de su Casa, y Corte, y a los diez y ocho días de estar en exercicio de esta Plaza, ordenándome venir en diligencia, como lo executé, llegando a esta Capital el dia 21 de Noviembre del año de 1748 por la noche, y en el mismo dia por la mañana salió de Chancillería el señor Dn. Juan de

${ }^{14} \mathrm{Cfr}$. J. F. Sanz Sampelayo: "El motin de Granada de 1748, ejemplo de un levantamiento popular debido a las subsistencias", en AHM Contemporánea 2-3, 1975-76, aunque no coincidimos en su juicio.

${ }^{15}$ F. 250 v. El relato de Cascajares en ff. 247-293. 
Ysla. Dió motivo a esta extraordinaria Real Resolución el bullicioso popular tumulto..."

Cascajares será uno de los más activos de estos Presidentes que intervienen en los problemas de urbanismo y economía de la ciudad. Sin olvidar nunca su suprema categoría, como en el caso de la visita que, contra la costumbre centenaria y prohibiciones legales, hace a Villalba, pero oído el Real Acuerdo y "por las circunstancias del tiempo y facultades amplias, que trahia del Rey, que pocas veces se han concedido iguales". Detalla los altísimos honores que con este motivo le hizo rendir el Teniente General. La sequía prolongada, que no cesa hasta la primavera de 1750, va acompañada de un aumento del número de pobres. Dicen los Anales: "Este año fue riquísimo, valió el pan a 10 cuartos; el carnero a 15 cuartos la libreta, y todo lo demás muy caro». Promoverá la creación del Hospicio:

«A poco tiempo de mi residencia en esta Ciudad heché menos una Casa Hospicio para toda clase de Pobres mendigos... y sin embargo de esto, y de las muchas insinuaciones, que he hecho a el mismo señor Marqués (Ensenada) no se ha tomado providencia sobre este establecimiento; y para que se logre convendrá, que el Sr. Presidente mi Sucesor continue sus instancias, y Yo las haré personalmente en la Corte..." ${ }^{16}$.

En 1754, con otro Presidente ya, se lograría, aunque instalado en el mismo edificio del Hospital Real.

Se ocupó de una plaga de langosta en el NE de la Región y de enfermedades en Málaga y Motril, caso en que "llegó a tanto la voz, que graduava las enfermedades de epidemia contagiosa". Impulsará obras en la Alhóndiga de granos; el empedrado de la Plaza de Bibrambla y adecentamiento de sus puestos de venta de frutas; el poner margen al Genil con sus acequias para evitar inundaciones aunque muchos «la han resistido sin otra razón que por precisarles a que contribuyesen con 10 que justamente se les havia repartido por el aprovechamiento de las aguas". A él se debe el edificio que actualmente es el de la Diputación Provincial, Palacio de Bibataubín apoyado en la vieja torre y puerta mo-

\footnotetext{
${ }^{16}$ F. 272 v.
} 
risca, que se va construir para cuartel de «tropa estante, y transeunte» y cuyas obras no llevaba bien el Corregidor-Intendente. $Y$ su intento de abastecer de agua suficiente al Albaicín. La formación de un Archivo para, al menos, la documentación del Real Acuerdo. La reparación del camino a Jaén. La ídem del Puente (-bóveda) sobre el Darro enfrente de la Chancillería. Otra nueva concordia Ciudad-Maestranza para las corridas de toros, "quedando por este medio en perfecta unión y alianza para lo sucesivo" según escribe con excesiva ingenuidad el Presidente. Redacta una Ordenanza para el Pósito, que hasta entonces se regía por la de Sevilla. Incluso omite "varios asuntos, que serian dignos de referirse en este libro; pero la estrechez del tiempo, y estar disponiendo mi viage para mañana me lo impiden". Lo que no es óbice para que dedique algunos folios finales a la gestión que él y Simón de Baños, presidente de Valladolid y antes Oidor de Granada, llevan ante el Consejo con el fin de ser equiparados con los Fiscales de éste que a los tres años de servicio obtenían plaza de Consejeros, "siendo el empleo de los suplicantes quando menos de tanta graduación, honores, y circunstancias como el de los Fiscales, de igual o mayor trabajo y de más crecidos dispendios". Pero habrán de esperar hasta 1756, siendo su sucesor el primer beneficiario. "Es un ministro de especial habilidad" puede leerse en uno de los Informes.

1752-1756. MANUEL ARREDONDO CARMONA. Nacido en 1700. De la Orden de Santiago. Catedrático en Valladolid. Fiscal y Oidor en aquella Chancillería (1737). Alcalde de Corte (1748). Su hermano Miguel será nombrado Alcalde del Crimen de Granada pocos meses antes de dejar la Presidencia. En la que podemos destacar - para la que nos falta el Libro Secreto sin que podamos discernir por qué se omitieron los correspondientes folios al encuadernar el volumen pues no parece lógico que los Presidentes dejaran de reseñar su gestión y tengamos que acudir a la brevedad de los Anales- que a su final la ciudad sufrió el espanto, al menos, del terremoto de Lisboa (1755):

«En Granada fue donde menos daño hizo; sólo en la Iglesia Colegial del Salvador la lastimó de forma que los Canónigos la dejaron y trasladaron su Colegial».

También que, como pacificador, logrará que la ciudad vuelva a asistir a la procesión del Corpus. Que durante su mandato tendrá como huésped distinguido pero forzoso en la Alhambra a Ensenada caído en des- 
gracia, quien deberá presentársele cada día. En 1756 se colocará, debidamente reparado para otros sesenta años, el reloj que corona la fachada de la Chancillería. Menos éxito tendrá, para desgracia de los actuales investigadores, en sus gestiones para formar un Archivo general que pusiera freno a las enormes pérdidas que habia sufrido y seguirá sufriendo casi hasta nuestros dias ${ }^{17}$. De interés socio-cultural son el comienzo de los descubrimientos de falsos restos de la Granada romana, como veremos más adelante.

1756-1760. JOSÉ MANUEL DE VILLENA Y GUADALFAXARA. Colegial del de Oviedo en Salamanca. Sará de la Orden de Calatrava y Marqués de Montenuevo y de Gauna (o Gaona). Era hermano del Marqués del Real Tesoro. Oidor de Valladolid (1744). Regente de Sevilla (1752). Manuel de Villena tampoco ha querido o podido que lleguen a nosotros detalles de su Presidencia granadina. Durante ella habrá una plaga de langosta que durará dos años (1756-58); un ciclón (1759); lluvias torrenciales (diciembre 1759-enero 1760).

1760-1766. ANDRÉS DE MARAVER Y VERA. Colegial del de Cuenca en Salamanca. Regente de Navarra. Sólo éstos son los escuetos datos que nos proporciona la documentación granadina. Harto más lamentable cuando su Presidencia coincide con los primeros años del reinado de Carlos III, con todo lo que de nuevo estilo pudo significar para la Chancillería granadina.

1766-1770. FERNANDO JOSE DE VELASCO Y CEBALLOS $Y$ FERNÁNDEZ DE ISLA. Nacido en 1707. Colegial del Arzobispo en Salamanca (1726). Casado dos veces. Alcalde del Crimen de Zaragoza (1739). Oidor de Valladolid (1752). Fiscal de Alcaldes de Corte (1760). Llegamos ahora al más interesante de los Presidentes del XVIII y ello por ser el que nos ha dejado la más vivaz descripción de su gestión de las cuatro que contiene el Libro Secreto, pero «no precisamente por el orden chronológico, sino es conforme fueren las expecies presentándose a la memoria, y con llamada, o reclamo a los documentos". De menuda letra, está distribuida en 57 capítulos $^{18}$. El mismo nos hace su curriculum en

17 Para el asunto del Archivo cfr. P. GAN, Chancilleria, 46-47.

${ }_{18}$ Una biografía reducida a los antecedentes familiares de Velasco es la de M. SOLANA, en el Bol. Bibl. Menéndez Pelayo, 1925. La narración de Velasco en ff. 295-311. 
portada hasta que llega a Presidente de Granada con 58 años. Honor que sólo se ve empañado por hallarse "embarazadísimo con mi numerosa, y selecta libreria", cuyo traslado sería costoso y podría causarle daños para sólo los cuatro o cinco años que solía durar el cargo. Tras muchas gestiones pudo depositarlos, bien identificados con «nombre, apellido, y armas que me corresponden", en el Colegio de Nobles. Luego se venderían al Marqués de la Romana, yendo a parar a Valencia, aunque hemos encontrado más de uno que le perteneció tanto en la Universidad de Granada como en la Biblioteca Nacional y llevan su escudo y ex-libris que reza: Ex Biblioteca D. Ferdinandi Josephi a Velasco. In Aula Criminali Supremi Castellae Senatus Fiscalis. Hombre vigilante y activo verá enseguida el mal estado de los caminos al entrar en Andalucía por Linares y escribe a su Corregidor sin esperar, sino en una de las ventas de la ruta para que se repare. En Maracena, junto a Granada, le reciben dos de sus compañeros de Colegio y Velasco no deja de mencionar, como buen gourmet, que probablemente era "una explendidísima cena de carne y pescado, con su correspondiente desert y ramillete". Sin embargo, su vida social no será fácil en una ciudad de carácter poco abierto como es Granada. Su segunda esposa, doña Paula de Quevedo, recibe la visita de las damas distinguidas que acuden a cumplimentarla. Pero se equivocó al introducir la novedad, imitando lo hecho por la mujer del Presidente del Consejo, conde de Aranda, de no ser ella quien las invitase «por esquelas» con el fin de que ninguna al no recibirlas se considerase desairada. O también que no acudiesen y lo fuera la Presidenta. El resultado fue que en adelante ambos tuvieron que sufrir un cierto vacio:

"Nos fueron plantando poco a poco, de modo que las más de las noches apenas se podia armar una religiosa (sic) mesa de Mediator en el quarto de mi Parienta" 19.

Pasando a la esfera oficial, su continua y muchas veces polémica actividad está también determinada por la cronología de su mandato y porque coinciden Aranda en el Consejo y Velasco en Granada. En el Conde se apoyará Velasco cuando vea frenada su gestión por otros poderes granadinos o madrileños. Cuando se aproxima el final de su mandato escribe:

${ }^{19}$ F. 303. 
"Si ubiera de referir por menor los innumerables informes, encargos graves, y cartas de oficio, que se me han pedido, hecho y escrito por las Secretarias... durante el tiempo de mi empleo, y dexar juntas todas estas correspondencias, seria un proceder en infinito; y no bastarian tres gruessos volúmenes en folio para contenerlas" ${ }^{20}$.

Lo primero fue conocer a todo el personal subalterno, con sus corruptelas y algunas virtudes también. Son páginas muy curiosas:

«Pero a lo que sobre todo me dediqué con más especialidad, desde que comencé a serbir el empleo, fue a obserbar el caracter y conducta de los individuos, y subalternos» 21 .

Indiquemos algunos de estos múltiples asuntos. Por ejemplo, le cupo informar al Consejo sobre la pretensión de la Universidad de ocupar el Colegio de San Pablo, magnífico edificio de los Jesuitas. Ya en 1767 había informado sobre programas y profesores universitarios y ahora lo hará favorablemente. Cuando en junio de 1769 se haga el solemne traslado, el claustral Dr. Berruezo lo agradecerá al Rey en una elocuente Oratio. Ahora han transcurrido más de dos siglos y la Universidad granadina ha tenido en su expansión que distribuirse por diversos puntos de la Ciudad y su extrarradio, pero como lo más importante de aquel expolio queda la rica Biblioteca, que también entró en la cesión y se hizo accesible al público. Por otra parte Velasco aprovechará esta ocasión para intentar reactivar el asunto del Archivo ${ }^{22}$. Pues ahora debería contener "los papeles concernientes a la venta de las tempralidades Jesuíticas". $Y$ no sólo esto. El erudito Presidente tenía también vocación de historiador:

“Por satisfacer mi curiosidad tan savida en todas materias dignas de no ignorarse, procuré acercarme desde el principio de mi Presidencia a investigar el de este supremo tribunal, sus Progresos, regalias, leyendo los papeles, y Libros secretos antiguos y modernos de sus Acuer-

\footnotetext{
${ }^{20} \mathrm{~F} .308$.

${ }^{21}$ FF. 297-302.

${ }^{22}$ F. 302 v.
} 
dos... De todos los quales he entresacado las copias que me han parecido más del caso..." ${ }^{23}$.

¿Llegaria a redactar algunos folios de esta historia? Cuando en 1791 el Fiscal Sempere y Guarinos llegue a Granada y haga otro intento de historiar la añeja institución hace muy poco tiempo de la muerte de Velasco y tampoco muestra en sus breves Observaciones (Granada 1796) tener noticia. Pero los más interesantes folios son los muchos que dedica a un tema que hoy sí es histórico y entonces fue su principal problema granadino. Se trata de su enfrentamiento con la Real Maestranza de Caballería. Los motivos: corridas de toros, construcción de una plaza fija aunque de madera, escándalos públicos y aún privados de algunos representantes de estos nobles y caballeros granadinos. El conjunto va más allá de lo meramente local para pasar a incorporarse al cambio social que está experimentando la España de finales del Antiguo Régimen. Pero no vamos a entrar en detalles de esta pugna pues ha sido objeto de estudio muy recientemente ${ }^{24}$.

Velasco termina su relato con unas líneas asimismo muy religiosas:

«Ha querido Dios concederme tal robustez de cuerpo y cabeza, que he logrado dar vado a todo; trabajando sin discontinuazión aun por las tardes, y pasándose muchos meses enteros sin salir de casa... Assi se lo ruego fervorosamente a la Santísima Trinidad... Puríssima Virgen Santa María... Amén".

Su marcha de Granada tampoco fue tranquila. Sufrió un atentado en el camino, que no hemos podido aún aclarar ${ }^{25}$. Será Académico de la Historia y de la Orden de Carlos III. Muere en 1789.

De los seis restantes Presidentes de Granada en el siglo XVIII al faltarnos tan valiosa fuente apenas si puede hacerse su ficha personal.

\footnotetext{
${ }^{23}$ F. 307.

${ }^{24}$ I. ARIAS de SaAvedra: La Real Maestranza de Caballeria de Granada en el siglo XVIII, Granada 1988. P. GAN: "Chancilleria y Maestranza en la Granada del XVIII", en Revista del Centro de Est. Hcos, de Granada, 2 (segunda época), Granada 1988.

${ }^{25} \mathrm{Cfr}$. P. GaN, Chancilleria, $5 \uparrow \mathrm{n}$.
} 
1770-1773. ALEJANDRO DOMINGO DE ZEREZO Y NIEVA. De la orden de Santiago. Regente de Sevilla. Aparte de tener asegurada su plaza en el Consejo de Castilla, será el que reciba en la primera promoción (1772) la Orden de Carlos III, como leemos en los Anales:

“...doscientas plazas de Caballeros pensionados... y venida la orden a D. Ignacio Bermúdez de Castro, Corregidor de Granada para que les pusiera las Cruces haciendo de Canciller, se puso en ejecución el dia 2 de Mayo".

Ya por entonces se ha acentuado más si cabe el control de la Chancillería por el Consejo a través de su Presidente. Zerezo será facultado para mudar la composición de las Salas, que antes se articulaban según la antigüedad de los Oidores y ahora lo harán según los criterios que se le señalan desde Madrid ${ }^{26}$.

1773-1777. MANUEL DO(L)Z DE LA PLAZA Y FUNES. En Granada había sido Alcalde del Crimen (1761) y Oidor (1768). Del Consejo (1772). Durante su Presidencia se instruirá proceso contra los falsarios de documentos e inscripciones ya mencionados; caso del que nos ha quedado una excelente exposición coetánea ${ }^{27}$. Pasarán tres años hasta que recaiga sentencia.

1777-1785. JERÓNIMO DE VELARDE Y SOLA. Madrileño. Colegial y Catedrático de Alcalá. De la orden de Santiago. Fiscal de Oviedo (1762). Oidor de Valladolid (1766). Regente de Mallorca (1773) y Cataluña (1774). Honores del Consejo (1783). Gobernador de Alcaldes (1787) muere en 1799. Breves datos de un artículo de revista ${ }^{28}$.

1785-1790. JUAN MARIÑO DE LA BARRERA. Alcalde de Corte. De la orden de Carlos III. Nombrado también Visitador de la Chancillería que

26 Ibidem.

27 Razón del juicio..., que se atribuye a PEREZ BAYER. Madrid 1781. Ultimamente $M$. Sotomayor: Cultura y picaresca en la Granada de la llustración. D. Juan de Flores y Oddouz, Granada 1988.

${ }^{28} \mathrm{M}^{\mathrm{a}}$ A. Pérez Samper: “Los Regentes de la R. Audiencia de Cataluña», en Pedralbes, 1. Barcelona 1981. 
preside. Los últimos años del reinado de Carlos III son ya más difíciles y, a imitación de lo existente en Madrid, funda las Diputaciones de Caridad. En la portada de su Reglamento (1786) se destaca la beneficencia del Presidente, aunque también que se debian a un acuerdo de la Junta General de Caridad. Cuando ya está nombrado para plaza del Consejo se dictarán las dos Pragmáticas Sanciones por una de las cuales se ampliaba el territorio con su jurisdicción de la Audiencia de Sevilla y por la otra se creaba la Audiencia de Extremadura en Cáceres ${ }^{29}$.

1790-1794. BENITO PUENTE. Alcalde de Corte. A él se dirigirá el Fiscal Sempere para su tarea de investigación histórica ${ }^{30}$.

1794-1800. CRISTÓBAL DE LA MATA. Fiscal de Galicia. Alcalde de Corte. Con él llegamos al último Presidente granadino del siglo XVIII y al penúltimo de la larga serie comenzada en el tránsito del siglo XV al XVI. Pues cuando en 30 de noviembre de 1800 un R. Decreto adscribía la Presidencia a la persona de los Capitanes Generales, va a salir de Granada el último, José Maria Puig de Samper. Se creaba también la figura del Regente, encargado sólo de la esfera judicial, que no es equiparable a la vieja figura del Decano de tiempos pasados y en cuya relación hasta 1834 apenas si habrá alguna figura destacada. Lo mismo que ocurre con los Capitanes Generales-Presidentes, a los que pronto la invasión francesa y luego los múltiples y de tan contrario signo vaivenes políticos, tampoco permitirán desarrollar una labor meritoria ${ }^{31}$.

${ }^{29}$ Cfr. P. GAN, Chancilleria, 51-53.

${ }^{30}$ Ibidem, 14-15.

${ }^{37}$ Como el Regente Fernández del Pino o el Capitán General Conde de Montijo. Cfr. P. GaN, Chancilleria, 54-62. 